\title{
An Overview of Wind Mills
}

\author{
Vipul Todkar ${ }^{1}$, Gurunath Shinde ${ }^{2}$, Sandeep Kamble ${ }^{3}$, Pradip Gunavant ${ }^{4}$ \\ UG Student, Mechanical Engg, Department, Sinhgad College of Engineering, Korti, India ${ }^{1}$ \\ Assistant Professor, Mechanical Engg, Department, Dr. Daulatarao Aher College of Engg., Karad, India ${ }^{2,3,4}$
}

\begin{abstract}
There are number of sources for generation of power but in the recent years wind energy shown its potential as the clean source of energy and contributing to the high energy demands of the world. In this paper we present an historical background of wind turbine and over view on its type .review of wind mills topic are chosen because wind energy is renewable resource and wind energy is cheap and is largely dependent upon manufacturing, distribution and building of turbines. Wind turbine having main two types that is horizontal axis wind turbine (HAWT) and vertical axis wind turbine (VAWT). The horizontal axis wind turbine cannot be used for household purpose, it required more space for installation.
\end{abstract}

Keywords: HAWT, Turbine, VAWT, Wind Mill.

\section{INTRODUCTION}

From 7th and 10th century various sources of wind power first constructed by the French aeronautical engineer are placed in the areas between today's Iran and Georges jean Marie durries in 1931.The world first mega Afghanistan to use of pumping of water or grind wheat. watt sized wind turbine was built in 1941 and connected to They had vertical axis and used the drag component of the local electrical distribution system in a mountain in wind power: because of their lower efficiency. After some Castleton, Vermont, USA. Up until this point, horizontal time work in a proper direction the part rotating in axis wind turbine had been rotating counter- clockwise, opposite direction compared to the wind had to be but from 1978 a shift occurred, and now, in order to protected by a wall. Obviously, devices of this type can be present a coherent view, all the major horizontal axis used only in places with a main wind direction, because turbines rotate clockwise. The worlds first wind farm was there is no way to follow the variations. The first install in southern new Hampshire USA, in 1980 which is windmills built in Europe and inspired by the Middle East consist of a 20 wind turbines rating at $30 \mathrm{kw}$ each. In 2008 ones had the same problem, but they used an horizontal most powerfull on shore wind turbine having $7 \mathrm{mw}$ axis. So they substitute the drag with the lift force, making capacity which is built up by Enrcon company from their inventors also the unaware discoverer of germany. aerodynamics.

\section{EARLY DEVELOPEMENT}

\section{III.ADVANTAGES AND DISADVANTAGES}

First historical record of a wind mill is found in BC 1700 in Mesopotamia in the present day of iran and eraq. The first one to draw a wind turbine was the great mathematician hero of Alexandria from Egypt in AD 50, it has been discussed whether the wind mill actually existed, or if it was drawing. In seistan AD 700 present day iran , there are records from the first practical wind mills namely "the Persian windmill". The first historical references of a windmill were found in Europe dates to 1185 in Yorkshire, Great Britain.

The first real documentation was of the Chinese statesman Yehlu Chhu-Tshai in 1219. These windmills were quite similar to the Persian windmills, vertically axed. The reduced weighted steel blades where introduced in 1870 . The vertical axis wind turbine is first designed to generate the electricity in 1887 by the Scottish professor James Blyth in Glasgow, Scotland. To large scale wind generation of electricity was first attempted by Charles brush in 1887 Ohio, USA. The darrieous wind turbine was
A) Advantages:

- Wind energy is a renewable resource meaning that the Earth will continue to provide this and it's up to people to use it and harness it to best advantage.

- Wind energy is nothing new. It's a well-known method of using kinetic energy (wind) to produce mechanical energy and has been around for thousands of years since the Persians and later Romans were using windmills to draw water and grind grain.

- Wind energy is cheap and is largely dependent upon the manufacturing, distribution and building of turbines for the initial costs.

- The electricity also produce from coal fired power plant and due to this green house gases are produce global warming instead of this we use wind energy.

- Wind turbines can also share space with other interests such as the farming of crops or cattle.

- Wind energy is creating jobs that are far outpacing other sectors of the economy. 
IARJSET

B) Disadvantages:

- Some people object to the visual site of wind turbines disrupting the local landscape.

- The initial cost of a wind turbine can be substantial, though government subsidies, tax breaks and long-term costs may alleviate much of this.

- The wind doesn't blow well at all locations on Earth. Wind maps are needed to identify the optimal locations.

- For the storage of wind energy we required batteries .

- Depending upon the type of wind turbine, noise pollution may be a factor for those living or working nearby.

- Some environmentalists have complained that it effects on migratory bird flight paths.

- The initial cost of a wind turbine can be substantial, though government subsidies, tax breaks and long-term costs may alleviate much of this.

\section{IV.TYPES OF WIND MILLS}

\section{A. Horizontal Axis Wind Turbine}

a. Definition:

The horizontal wind turbine is a turbine in which the axis of the rotor is parallel to the wind stream and the ground. Most HAWTs today are two- or three-bladed, though some may have fewer or more blades.

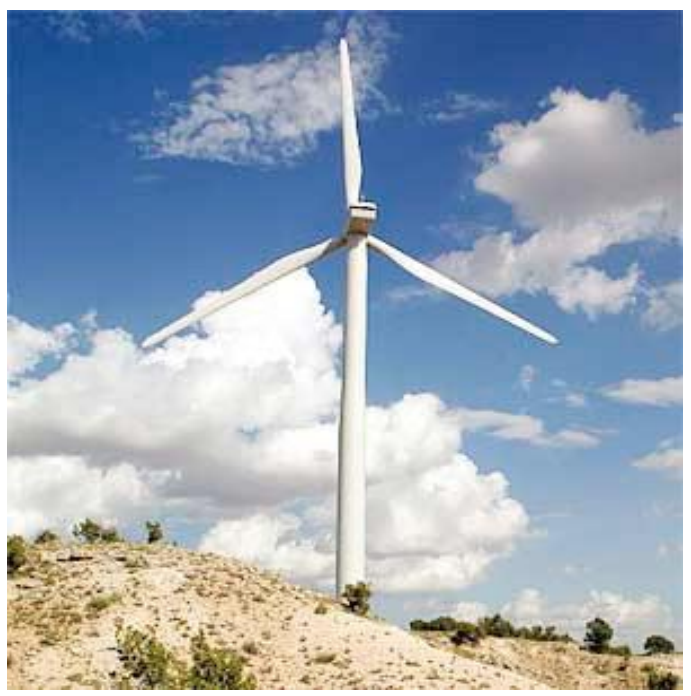

Figure 1 Horizontal Wind Mill

b) Types of Horizontal Axis Wind Turbines:

1) Upwind turbine:

The upwind turbine is a type of turbine in which the rotor faces the wind. A vast majority of wind turbines have this design. Its basic advantage is that it avoids the wind shade behind the tower. On the other hand, its basic drawback is that the rotor needs to be rather inflexible, and placed at some distance from the tower. In addition, this kind of HAWT also needs a yaw mechanism to keep the rotor facing the wind.

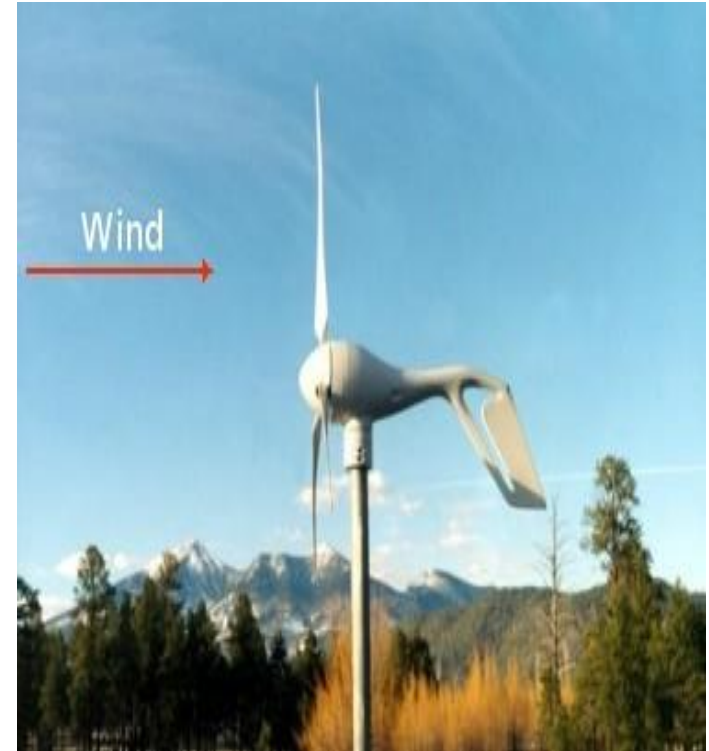

Figure 2 Upwind Wind Mill

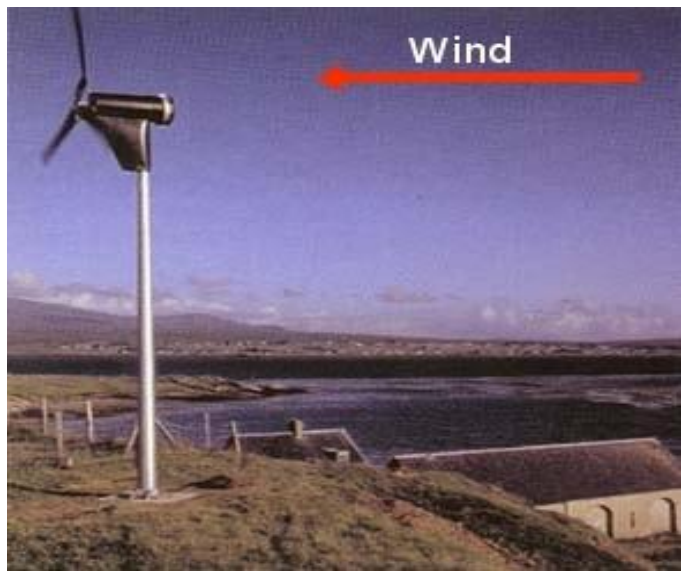

Figure 3 Downwind Mill

2) Downwind turbine:

The downwind turbine is a turbine in which the rotor is on the downwind side (lee side) of the tower. It has the theoretical advantage that they may be built without a yaw mechanism, considering that their rotors and nacelles have the suitable design that makes the nacelle follow the wind passively. Another advantage is that the rotor may be made more flexible. Its basic drawback, on the other hand, is the fluctuation in the wind power due to the rotor passing through the wind shade of the tower.[1]

\section{3) Non standard HAWT:}

With this glimpse of what a standard wind turbine should be, everything else is non-standard: There is no horizontal axis of rotation. The number of blades is other than three (one, two, or more than three). In this case, drag forces plays important role. The arrangement of rotor is for downwind. And for tower it is upwind. It is designed for constant speed operation. So it is called stall control after rated power is reached. From these characteristics, we may derive a large number of different designs. Only a few of 
IARJSET

them became popular enough to acquire their own names. The Darrieus turbine is then powered by the lift forces The American or Western-type turbine, number of blades produced by the airfoils. The blades allow the turbine to which in most cases are flat plates with a small angle reach speeds that are higher than the actual speed of the between plane of rotation and chord. These turbines were wind, thus, this makes them well-suited to electricity used mainly in the second half of the nineteenth century, generation when there is a turbulent wind.

see Fig 3.The Danish Way of extracting wind energy used most of the now classical properties with a fixed-pitch blade arrangement and a constant RPM operation mode.

The development of this design philosophy started in the 1940s and died off slowly in the 1990s.

4) Small wind turbine:

Small wind turbines are defined by IEC as a wind turbine with a rotor swept area no greater than $200 \mathrm{~m} 2$. Therefore, the diameter is limited to $16 \mathrm{~m}$. However, most of them have much smaller diameters starting at about $1 \mathrm{~m}$. More can be found in. Figure 4 gives an account of scaling. The main problem with safety approval is that it offers two very different methods, first is the usual aero elastic simulation modelling and second is a simplified load model. The first one implies the same amount of work as for a state-of-the-art turbine and is not economical in most cases.

\section{B. Vertical Axis Wind Turbine:}

\section{Definition}

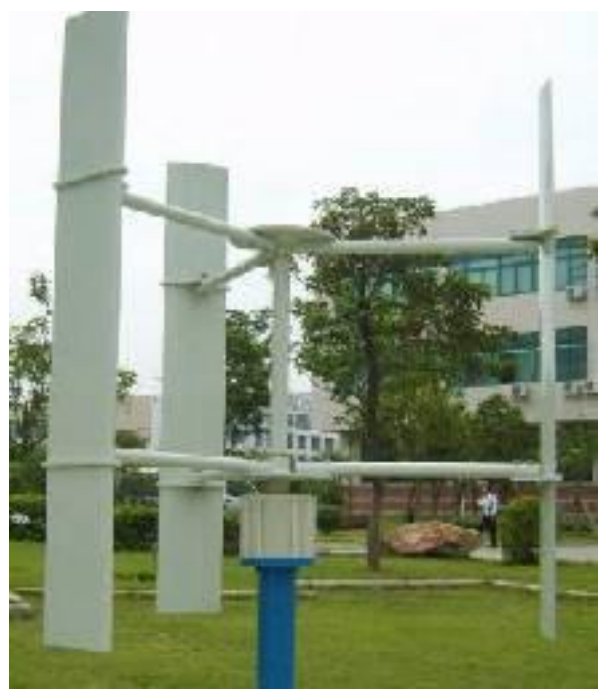

Figure 5 Giromill Wind Mill

The vertical axis wind turbine is an old technology .its starts from almost 4000 years ago in the HAWT the rotor is rotated along horizontal axis but in the VAWT the rotor is rotated along vertical axis. The VAWT is not as efficient as HAWT because it required high speed of wind but HAWT can run also in low weight situation. As compared to HAWT the VAWT can be built easily and also it can be mountain close to the ground. If we consider above handle turbulence it is better than HAWT. It has maximum efficiency is $30 \%$ so it just use for privet use.There are three types of vertical Axis Wind Turbines:

\section{Darrieus Turbine:}

The Darrieus turbine is composed of a vertical rotor and several vertically oriented blades. A small powered motor is required to start its rotation, since it is not self-starting. When it already has enough speed, the wind passing through the airfoils generate torque and thus, the rotor is driven around by the wind.

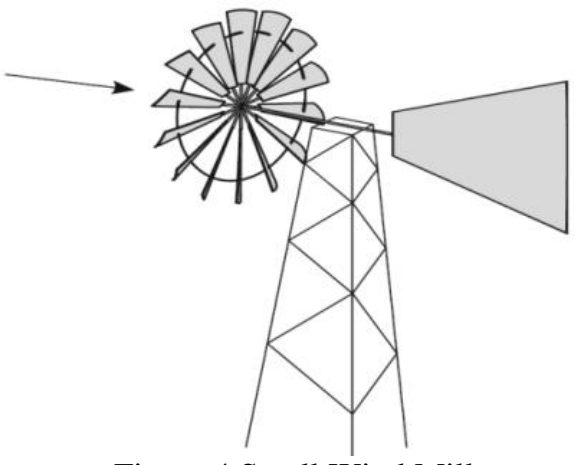

Figure 4 Small Wind Mill
2. Giromill Turbine:

The Giromill Turbine is a special type of Darrieus Wind Turbine. It uses the same principle as the Darrieus Wind Turbine to capture energy, but it uses 2-3 straight blades individually attached to the vertical axis instead of curved blades. It is also applicable to use helical blades attached around the vertical axis to minimize the pulsating torque.

\section{Savonius Turbine:}

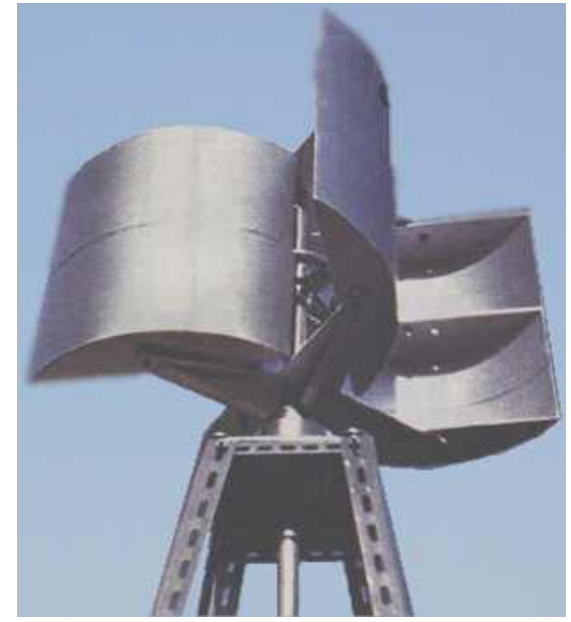

Figure 6 Savonius Wind Mill

The Savonius wind turbine is one of the simplest turbines. It is a drag-type device that consists of two to three scoops. Because the scoop is curved, the drag when it is moving with the wind is more than when it is moving against the wind. This differential drag is now what causes the Savonius turbine to spin. Because they are drag-type 
IARJSET

International Advanced Research Journal in Science, Engineering and Technology

National Conference on Design, Manufacturing, Energy \& Thermal Engineering (NCDMETE-2017)

AGTI's Dr. Daulatrao Aher College Engineering, Vidyanagar Extension, Karad

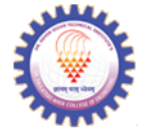

Vol. 4, Special Issue 1, January 2017

devices, this kind of turbine extracts much less than the wind power extracted by the previous types of turbine.[2]

\section{ADVANTAGES DISADVANTAGES OF HAWT AND VAWT}

A) Advantages of the HAWT:

1. Blades are to the side of the turbine's center of gravity, helping stability

2. The turbine collects the maximum amount of wind energy by allowing the angle of attack to be remotely adjusted.

3. The ability to pitch the rotor blades in a storm so that damage is minimized

4. The tall tower allows the access to stronger wind in sites with wind shear and placement on uneven land or in offshore locations

5. Most hawts are self-starting

B) Disadvantages of the HAWT

1. It has difficulties operating near the ground

2. The tall towers and long blades are hard to transport from one place to another and they need a special installation procedure

3. They can cause a navigation problem when placed offshore

C) Advantages of VAWT

1. Since VAWT components are placed nearer to the ground, it has an easier access to maintenance

2. It has smaller cost of production, installation, and transport

3. These turbine does not need to be pointed towards the wind in order to be effective

4. VAWTs are suitable in places like hilltops, ridgelines and passes

5. Its blades spin at a lower velocity, thus, lessening the chances of bird injury

6. It is suitable for areas with extreme weather conditions like mountains

D) Disadvantages of the VAWT

1. Most of them are only half as efficient as HAWTs due to the dragging force

2. Air flow near the ground and other objects can create a turbulence not flow, introducing issues of vibration.

\section{CONCLUSION}

In this paper an overview of wind mills are explained. Advantages and disadvantages of Horizontal and Vertical wind mills are discussed. Wind power can be seen as the alternative renewable source of energy.

\section{REFERENCES}

[1] Robert Threshera , Michael Robinsona and Paul Veers, "Wind Energy Technology: Current Status and R\&D Future", A national laboratory of the U.S. Department of Energy Office of Energy Efficiency \& Renewable Energy, 1-2 March 2008

[2] D. Corbus and M. Meadors, "Small Wind Research Turbine", A national laboratory of the U.S. Department of Energy Office of Energy Efficiency \& Renewable Energy, October 2005

[3] www.cea.nic.in

[4] http://www.cwet.tn.nic.in/html/departments_ewpp.html

[5] Reassessing Wind Potential Estimates for India: Economic and Policy Implications by Amol Phadke, Ranjit Bharvirkar and Jagmeet Khangura; Lawrence Berkeley National Lab (2012)

[6] www.recregistryindia.in

[7] www.isgtf.in/

\section{BIOGRAPHY}

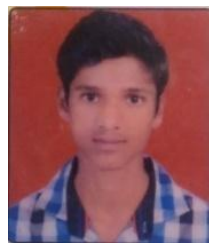

Mr. Vipul Todkar is final year student of Mechanical Engineering department from Sinhgad College of Engineering, Korti, Solapur University, Maharashtra, India. 